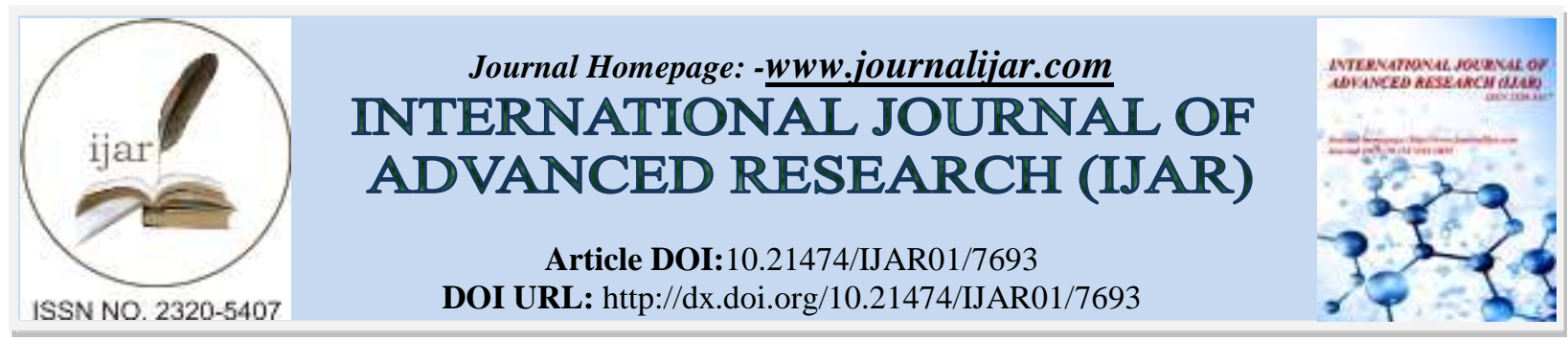

RESEARCH ARTICLE

\title{
LIPID PROFILE AND OXIDATIVE STRESS STATUS IN CEREBROVASCULAR ACCIDENT PATIENTS.
}

\author{
Ahmed W. Al-khalifa, Dr. Majid A. Maatook and Dr. Abdulkareem M. Jewad. \\ Department of Medical Laboratory Technology, College of Health and Medical Technology, Southern Technical \\ University, Basrah / Iraq.
}

\section{Manuscript Info}

Manuscript History

Received: 19 July 2018

Final Accepted: 25 August 2018

Published: September 2018

Keywords:-

Cerebrovascular accident, Lipid profile, Oxidative stress, antioxidant enzymes, Trace elements.

\section{Abstract}

Stroke is a serious life threatening condition, which continues to be a major public health problem leading to death and severe neurologic disability, therefore the present study was aimed to study the lipid profile, oxidative stress and antioxidant enzymes in cerebrovascular accident (CVA) patients. The study was carried out in the Department of Medical Laboratory Technology in Southern Technical University. 5-7 ml of Blood was drawn into gel tube and was utilized for estimation of lipid profile parameters, oxidative stress marker concentration and antioxidant enzymes activities. The mean values of TC, TG, LDL-c, VLDL-c, SOD, GPx and CAT were significantly increased in CVA patients as compared to control group $(\mathrm{p}<0.05)$ and HDL was decreased in CVA patients as compared to control group ( $\mathrm{p}<0.05$ ). Serum MDA was significantly increase in CVA patients as compared to control group $(\mathrm{p}<0.05)$, serum iron was significantly decreased, while copper levels showed insignificant changes in CVA patients as compared to control group $(\mathrm{p}<0.05)$. The present study reveals the importance of determining the lipid profile, lipid peroxidation and antioxidant status in CVA patients to enable the formulation of specific therapies for early intervention and better management of disease.

Copy Right, IJAR, 2018,. All rights reserved

\section{Introduction:-}

Stroke or what is known medically as cerebrovascular accident (CVA) is the third cause of medically related mortality and the second leading cause of neurological morbidity (after Alzheimer disease) in the USA and Europe. It is the fourth most common cause of death in Singapore (Gutteridge and Halliwell, 2015). Stroke is the third most common cause of death in most western populations, after coronary heart disease (CHD) and cancer (CA), information on incidence, prevalence, morbidity and mortality of stroke is extremely important in the evaluation of priorities for dealing with this disease (Husain et al, 2014). During the past years, several observational studies and clinical trials have revealed the adverse effects of abnormal blood lipid and lipoprotein levels in the pathogenesis and progression of atherosclerosis and cardiovascular disease. Numerous population studies have shown an inverse correlation between plasma high-density lipoprotein (HDL) levels and risk of cerebrovascular disease (Mahato et al, 2016). Epidemiological studies have also shown that elevated concentrations of total cholesterol and low-density lipoprotein (LDL) in the blood are powerful risk factors for coronary disease (Ovbiagele and Nguyen, 2011). In view of the pathological role of increased lipid profile, Oxidative stress and decrease antioxidants status in the development and progression of cerebrovascular disease (CVD), Hence, the present study is designed to determine 
level of lipid profile, malondialdehyde, antioxidant enzymes (SOD, GPx and CAT) and trace elements (Iron and Copper) in CVA patients.

\section{Materials and Methods:-}

The study was carried out in the Department of Medical Laboratory Technology in Southern Technical University, Basra, Iraq. Cerebrovascular accident patients attending and admitted in neurology department during the period of November 2017 until the end of August 2018 to enrolled in this study. The diagnosis of cerebrovascular accident were based on CT and MRI.

\section{Exclusion criteria:}

1. Previous history of CVA.

2. Transient ischemic attack (TIA).

3. Intracranial hemorrhage.

4. History of infections and inflammatory disease.

5. Autoimmune or hematological disorder.

6. Use of lipid lowering drugs, immunosuppression or anti-inflammatory drugs in the previous 2 months.

\section{Inclusion criteria:}

All acute stroke patients.

\section{Samples collection:}

9-10 $\mathrm{ml}$ of fasting venous blood was drawn into vacutainers gel tube from the stroke patients and the control subjects. The sera was separated by centrifugation and was utilized for determination of lipid profile, MDA concentration, antioxidant enzymes (SOD, GPx and CAT) activities, iron and copper.

\section{Biochemical Analysis:}

A kit supplied by Biolabo Company, using fully automated clinical chemistry analyzer (Architect c4000, Abbott, Germany), measured serum lipid profile (TC, TG, LDL-c and HDL-c).

VLDL-C was calculated from the formula: VLDL-C=Triglyceride/5. (Tietz, 2014).

Serum Malondialdehyde (MDA) concentration was estimated by a kit supplied by Elabscience, USA.

Serum Superoxide dismutase (SOD) activity was estimated by a kit supplied by Elabscience, USA.

Serum Glutathione peroxidase (GPx) activity was estimated by a kit supplied by Elabscience, USA.

Serum Catalase activity was estimated by a kit supplied by Bioassay, USA.

A kit supplied by Architect, Germany estimated serum iron levels.

A kit supplied by Architect, Germany estimated serum copper levels.

\section{Statistical analysis:}

Statistical analysis between stroke patients (both ischemic and hemorrhagic) and control group were done by using SPSS, $t-$ test and the results were expressed as Mean (M), standard deviation (S.D.). Difference between the study group and control group were considered significant when the $\mathrm{p}$ value determined by $\mathrm{t}$ - test was less than 0.05 $(\mathrm{p}<0.05)$.

\section{Results and Discussion:}

Table 1: Clinical characteristics of all studied groups

\begin{tabular}{|l|l|l|l|l|}
\hline \multicolumn{2}{|l|}{ Parameters } & Ischemic & Hemorrhagic & Control \\
\hline \multicolumn{2}{|l|}{ Total (No.) } & 78 & 32 & 50 \\
\hline \multirow{3}{*}{ Sex } & Male & $51(54.8 \%)$ & $17(18.3 \%)$ & $25(26.9 \%)$ \\
\cline { 2 - 5 } & Female & $27(40.3 \%)$ & $15(22.4 \%)$ & $25(37.3 \%)$ \\
\hline \multicolumn{2}{|l|}{ Age (years) } & $62.02 \pm 15.29$ & $61.87 \pm 12.07$ & $55.88 \pm 13.12$ \\
\hline
\end{tabular}

Table 2: Comparison of serum lipid profile in control subjects and stroke patients.

\begin{tabular}{|l|l|l|l|l|}
\hline \multirow{2}{*}{ Parameters } & $\begin{array}{l}\text { Control } \\
\mathrm{n}=50\end{array}$ & \multicolumn{2}{|c|}{ Stroke Patients } & \multirow{2}{*}{ P value } \\
\cline { 2 - 4 } & $121.34 \pm 32.2$ & Ischemicn=78 & Hemorrhagic $\mathrm{n}=32$ & \\
\hline cholesterol $\mathrm{mg} / \mathrm{dl}$ & $176.7 \pm 51.15$ & $182.9 \pm 61.2$ & 0.001 \\
\hline Triglyceride $\mathrm{mg} / \mathrm{dl}$ & $103.4 \pm 30.29$ & $140.6 \pm 73.91$ & $143.28 \pm 60.18$ & 0.002 \\
\hline
\end{tabular}




\begin{tabular}{|l|l|l|l|l|}
\hline & & & & \\
\hline Serum HDL mg/dl & $41.95 \pm 6.82$ & $37.45 \pm 12.97$ & $38.3 \pm 20.36$ & 0.171 \\
\hline Serum LDL mg/dl & $88.8 \pm 23.35$ & $112.6 \pm 46.4$ & $107.84 \pm 49.63$ & 0.007 \\
\hline SerumVLDL mg/dl & $21.05 \pm 6.76$ & $28.36 \pm 14.5$ & $28.64 \pm 12.04$ & 0.002 \\
\hline
\end{tabular}

Table 3: Comparison of serum MDA, SOD, GPx, CAT, iron and copper levels in Control and stroke patients.

\begin{tabular}{|l|l|l|l|l|}
\hline Parameters & Control $\mathrm{n}=50$ & Ischemic & Hemorrhagic & P value \\
\hline $\begin{array}{l}\text { Serum MDA } \\
\text { ng/ml }\end{array}$ & $78.81 \pm 18.15$ & $198.1 \pm 136.8$ & $624.5 \pm 263.15$ & 0.049 \\
\hline $\begin{array}{l}\text { Serum SOD } \\
\text { pg./ml }\end{array}$ & $1848.2 \pm 870.7$ & $2264.21 \pm 571.9$ & $2314.52 \pm 607.2$ & 0.001 \\
\hline $\begin{array}{l}\text { Serum GPx } \\
\text { pg./ml }\end{array}$ & $82.21 \pm 24.58$ & $495.28 \pm 384.55$ & $442.03 \pm 353.95$ & 0.001 \\
\hline Catalase pg./ml & $1.77 \pm 1.01$ & $10.92 \pm 23.69$ & $15.33 \pm 24.09$ & 0.006 \\
\hline Iron $(\mu \mathrm{g} / \mathrm{dl})$ & $69.36 \pm 16.12$ & $37.1 \pm 23.16$ & $35.74 \pm 19.8$ & 0.001 \\
\hline copper $(\mu \mathrm{g} / \mathrm{dl})$ & $79.18 \pm 16.64$ & $86.49 \pm 22.31$ & $85.24 \pm 21.86$ & 0.14 \\
\hline
\end{tabular}

The total number was 160 subjects, and were categorized into two groups, first group consists of 110 patients with acute stroke and the second group consists of 50 apparently healthy control subjects. Table no.1: shows the clinical characteristics of all studied groups, 51(54.8\%) males with ischemic stroke and 17(18.3\%) males with hemorrhagic stroke, while $27(40.3 \%)$ females with ischemic stroke and $15(22.4 \%)$ with hemorrhagic stroke. The rest 50 subjects ( 25 males and 25 females) were considered as control The age distribution of ischemic stroke patients were $62.02 \pm$ 15.29 and $61.87 \pm 12.07$ for hemorrhagic stroke, while $55.88 \pm 13.12$ for control group.

Table no.2: shows that the mean levels of lipid profile in control group were TC $(121.34 \pm 32.2 \mathrm{mg} / \mathrm{dl})$, TG $(103.4 \pm 30.29 \mathrm{mg} / \mathrm{dl})$, HDL-c $(41.95 \pm 6.82 \mathrm{mg} / \mathrm{dl})$, LDL-c $(88.8 \pm 23.35 \mathrm{mg} / \mathrm{dl})$ and VLDL-c $(21.05 \pm 6.76 \mathrm{mg} / \mathrm{dl})$. In ischemic stroke patients, the mean levels were TC $(176.7 \pm 51.15 \mathrm{mg} / \mathrm{dl})$, TG $(140.6 \pm 73.91 \mathrm{mg} / \mathrm{dl})$, HDL-c $(37.45 \pm 12.97 \mathrm{mg} / \mathrm{dl})$, LDL-c $(112.6 \pm 46.4 \mathrm{mg} / \mathrm{dl})$ and VLDL-c $(28.36 \pm 14.5 \mathrm{mg} / \mathrm{dl})$. Hemorrhagic stroke patients the mean levels were TC $(182.9 \pm 61.2 \mathrm{mg} / \mathrm{dl})$, TG $(143.28 \pm 60.18 \mathrm{mg} / \mathrm{dl})$, HDL-c $(38.3 \pm 20.36 \mathrm{mg} / \mathrm{dl})$, LDL-c $(107.84 \pm 49.63 \mathrm{mg} / \mathrm{dl})$ and VLDL-c $(28.64 \pm 12.04 \mathrm{mg} / \mathrm{dl})$. We found, mean values of Total cholesterol, TG, LDL and VLDL-c were significantly increased in CVA patients as compared with control ( $\mathrm{p}<0.05)$. The mean level of HDL-c in CVA patients were insignificantly decreased as compared to control group $(\mathrm{p}<0.05)$. Our results of lipid profile were agreement with the result of Laloux et al., 2004, Ebraheem, 2016, Jasim et al., 2011, Sreedhar et al., 2010 and Mahmood et al,. 2010.

Table no.3: in the present study, serum MDA level in CVA patients (ischemic $198.1 \pm 136.8 \mathrm{ng} / \mathrm{ml}$, hemorrhagic $624.5 \pm 263.15 \mathrm{ng} / \mathrm{ml}$ ) were found to be significantly increased $(\mathrm{p}<0.05)$ as compared to control group $(78.81 \pm 18.15)$. This result was concurrent with findings Jawalekar et al., 2011, Beg et al., 2005. The serum level of superoxide dismutase in CVA patients (ischemic $2264.21 \pm 571.9 \mathrm{pg}$. $/ \mathrm{ml}$, hemorrhagic $2314.52 \pm 607.2 \mathrm{pg}$. $/ \mathrm{ml}$ ) were found to be increase as compare to control group $(1848.2 \pm 870.7 \mathrm{pg}$. $/ \mathrm{ml})$. Our results of SOD are concurrent with the findings of Gokdemir, 2017, Sheikh et al., 2009 and Chen et al., 2001. The serum glutathione peroxidase activity in CVA patients (ischemic $495.28 \pm 384.55 \mathrm{pg}$. $/ \mathrm{ml}$, hemorrhagic $442.03 \pm 353.95 \mathrm{pg}$. $/ \mathrm{ml}$ ) was found to be increased as compared to control group $(82.21 \pm 24.58 \mathrm{pg}$. $/ \mathrm{ml})$. Our results of GPx are concurrent with findings of Ha et al., 2011, Gokdemir, 2017 and Zimmermann et al., 2003. The mean values of serum CAT activity in CVA patients (ischemic $10.92 \pm 23.69 \mathrm{pg} . / \mathrm{ml}$, hemorrhagic $15.33 \pm 24.09 \mathrm{pg} . / \mathrm{ml}$ ) was significantly increased as compared with control $(1.77 \pm 1.01 \mathrm{pg} . / \mathrm{ml})$, our result were in agreement with the result of Sapojnikova et al., 2012 and Sheikh et al., 2009. The serum levels of iron was significantly decreased in CVA patients (ischemic $37.1 \pm 23.16 \mu \mathrm{g} / \mathrm{dl}$ ), hemorrhagic $35.74 \pm 19.8 \mu \mathrm{g} / \mathrm{dl})$ as compared with control group $(69.36 \pm 16.12 \mu \mathrm{g} / \mathrm{dl})$, our result were in agreement with Moustafa, 2011, Mehta et al, 2012. While serum levels of copper was increased in CVA patients (ischemic $86.49 \pm 22.31 \mu \mathrm{g} / \mathrm{dl}$, hemorrhagic85.24 $\pm 21.86 \mu \mathrm{g} / \mathrm{dl})$ as compared with control group $(79.18 \pm 16.64 \mu \mathrm{g} / \mathrm{dl})$, our result were in agreement with Moemeni et al., 2018, Li and Zhang, 2012. 


\section{Conclusion:-}

From the present study it was found that, the level of total cholesterol, triglyceride, low density lipoprotein and very low density lipoprotein in stroke patients were significantly higher as compared to control group $(\mathrm{p}<0.05)$. Levels of high-density lipoprotein was insignificantly elevated as compared to control group $(\mathrm{p}<0.05)$.

The marker of lipid peroxidation induced Malonaldehyde (MDA) was significantly higher in CVA patients as compared to control group $(\mathrm{p}<0.05)$

Levels of superoxide dismutase (SOD), glutathione peroxidase (GPx) and catalase (CAT) was significantly increased in CVA patients as compared to control group $(\mathrm{p}<0.05)$. The serum levels of iron was significantly decreased in stroke patients as compared with control group, while serum levels of copper shows insignificant increase in stroke patients as compared with control group. It appears that, both increase in lipid profile and MDA refers to, the stroke patients have considerable degree of oxidative stress.

The present study therefore reveals the importance of determining the lipid profile, oxidative stress and antioxidant status in CVA to enable the formulation of specific therapies for early intervention and better management of disease. The detection of risk factors in early stage and correction of disease condition will help the patients to improve, reduce further complications.

\section{References:-}

1. Asad Mahmood, Muhammad Ashraf Sharif, Muhammad Naeem Khan, Umar Zafar Ali, (2010). Comparison of Serum Lipid Profile in Ischemic and Hemorrhagic Stroke. Journal of the College of Physicians and Surgeons Pakistan, 20(5), 317-320.

2. Binod Mahato, Chaudhary B. L., Brij Nandan Singh, (2016). Study of lipid profile, enzymatic antioxidant and oxidative stress in cardiovascular diseases. International journal of Bioassay, 5(8), 4759-4762.

3. Bruce Ovbiagele, Mai N. Nguyen-Huynh, (2011). Stroke Epidemiology: Advancing Our Understanding of Disease Mechanism and Therapy. Neurotherapeutics, Springer, 8:319-329, 2011.

4. Zimmermanna C., Winnefeldb K., Streckb S., Roskosb M., Haberla R.L., (2004). Antioxidant Status in Acute Stroke Patients and Patients at Stroke Risk. Eur Neurol, 51, 157-161.

5. Carl A. Burtis, David E. Bruns, (2014). Tietz fundamentals of clinical biochemistry. Seventh edition, Elsevier Saunders, USA, 388-411.

6. Younis Esmaeel Ebraheem, (2016). Comparative lipid profile study between ischemic and hemorrhagic stroke. Tikrit Medical Journal, 21(1), 20-26.

7. Gul Sahika Gokdemir, Mehmet Tahir Gokdemir, Ali Ziya Karakilcik, (2017). Total oxidative stress, total antioxidant status and erythrocytes status in patients with acute ischemic stroke. Acta Medica Mediterranea, 33, 157-163.

8. Gutteridge John M. C., Halliwell Barry, (2015). Free radicals in biology and medicine. Fifth edition, Oxford University Press, 199-220.

9. Haider A. Husain, Hasan A. Al-Hamadani, Munther T. Hamzah, (2014). The relation of Hypokalemia to hypertensive and non-hypertensive ischemic stroke. Iraqi Journal of Medical Sciences, 12(2), 102-107.

10. Hojatollah Moemeni, Durdi Qujeq, Alijan Ahmadi Ahangar, Karimollah Hajian, Hadi Parsian, (2018). Evaluation of Serum Magnesium, Iron, Copper and Zinc Levels in Ischemic and Hemorrhagic Stroke Patients and Healthy Controls. Journal of Clinical and Basic Research, 2(1), 6-10.

11. Jawalekar S. L. J., Ujjwala J., Vasant T., Deshmukh Y. A., (2010). Status of Lipid profile, MDA and protein carbonyl in patients with cardiovascular diseases. Archives of Applied Science Research, 2, 8-14.

12. Sreedhar K., Banumathy Srikant, Laxmikant Joshi, Usha G., (2010). Lipid Profile in Non-Diabetic Stroke -A Study of 100 Cases. JAPI, 58, 547-551.

13. Laloux P., Galanti L., Jamart J., (2004). Lipids in ischemic stroke subtypes. Acta neurol. belg., 104, 13-19.

14. Lisa Ha, Amrit K. Sakhi, Siv Kjolsrud Bohn, Kjell Flekkoy, Rune Blomhoff, Per Ole Iversen, Truls Hauge, (2011). Antioxidant status after an acute stroke and the association with survival in elderly at nutritional risk. The European e-Journal of Clinical Nutrition and Metabolism, 6, 135-141.

15. Beg M., Ahmad S., Gandhi S., Akhtar N., Ahmad Z., (2005). A Study of Serum Malondialdehyde Levels in Patients of Cerebrovascular Accident. Journal, Indian Academy of Clinical Medicine, 6(3), 229-231.

16. Mohamed A. H. Jasim, Farah S. Saih, Shaima'a A. H. Jasim, (2011). Lipid Profile and Fatty-Acid Composition of Human Serum in Cerebrovascular Accident Patients in Iben-Sena Hospital-Mosul. Tikrit Journal of Pure Science, 16(2), 1-7. 
17. Nasrin Sheikh, Heidar Tavilani, Aliakbar Rezaie, Asad Vaisi-raygani, Saeedeh Salimi, (2009). Relationship between Estradiol and Antioxidant Enzymes Activity of Ischemic Stroke. Journal of Biomedicine and Biotechnology, 1-5.

18. Nelly Sapojnikova, Nino Asatiani, Tamar Kartvelishvili, Iagor Kalandadze, Alexander Tsiskaridze, (2012). Plasma Antioxidant Activity as a Marker for a Favorable Outcome in Acute Ischemic Stroke. Science and Technology Centre, Ukraine, 141-168.

19. Preema J. Mehta, Sherita Chapman, Annapurni Jayam-Trouth, Mohankumar Kurukumbi, (2012). Acute Ischemic Stroke Secondary to Iron Deficiency Anemia. Case Reports in Neurological Medicine, 1-5.

20. Shatha Rouf Moustafa, (2011). Biochemical Estimation of Trace Elements Manganese (Mn), Cobalt (Co), Calcium (Ca) and Iron (Fe) in Patients with Cardiovascular Diseases. Tikrit Journal of Pure Science, 16(4), 118-123.

21. Xin Chen, Rhian M. Touyz, Jeong Bae Park, Ernesto L. Schiffrin, (2001).Antioxidant Effects of Vitamins C and E Are Associated With Altered Activation of Vascular NADPH Oxidase and Superoxide Dismutase in Stroke-Prone. Hypertension, journal of American heart association, 38(2), 606-611.

22. Yang V. Li and John H. Zhang, (2012). Metal Ions in Stroke Pathophysiology. Springer, New York, 1-12. 